\title{
Sağlık Hizmetleri Meslek Yüksekokulu Öğrencilerinde Elektroensefalografi Algisı
}

\author{
Electroencephalography Perception in Health Services School Students
}

\author{
Halil SOYAL, Cüneyt BAŞBUĞU, Göksel SOMAY
}

\section{ÖZ}

İnsan beyninde çok düşük seviyelerde devamlı elektrik dalgaları üretir ve bu dalgalar düzenli olarak beyinde yayılır. Elektroensefalografi (EEG), beyindeki elektriksel dalgaların değişiminin bilgisayar ortamında kaydedilmesidir. Bu çalışma, Okan Üniversitesi Sağlık Hizmetleri Meslek Yüksekokulunun değişik alanlarında öğrenim gören sağlık teknikeri adaylarının, Elektroensefalografi konusunda bilgilerini değerlendirmek ve EEG algılarını incelemek amacıyla yapılmıştır. Araştırmada veri toplama arac1 olarak Elektronörofizyoloji programı öğrencileri tarafından yürütülen anket çalışması kullanılmıştır. Araştırma sonucunda, sağlık kuruluşlarında yaygın olarak kullanılmakta olan EEG'nin niteliği, kullanım alanları ve oluşturduğu algının farklı olduğu gözlenmiştir.

Anahtar Kelimeler: Elektroensefalografi, Elektronörofizyoloji, Sağlık Hizmetleri Meslek Yüksekokulu

\begin{abstract}
The human brain keeps on producing nonstop electricty which propagates through all brain. Electroencephalography (EEG), is the physiological method of choice to record all of the electrical activity generated by the brain from electrodes placed on the scalp surface. This study is realized in order to evaluate the knowledge of the students of Okan University Vocational School of Health Services on electroencephalography and in order to examine their perception of EEG. In the study, an inquiry is used as a data collection mean which was carried out by Electroneurophysiology Department students. The results have showed the existance of different perceptions among health service students on the EEG which has a vast use in health institutions.
\end{abstract}

Keywords: Electroencephalography, Electroneurophysiology, Vocational School of Health Services

\section{GİRIŞ}

Sağlık alanında yeni yatırımların artması, sağlık kurumlarına yapılan teknolojik yatırımlardan televizyon programlarında ve reklam panolarında sıklıkla söz edilmesi, kurumlar arasında rekabeti arttırmakta ve bu kurumların niteliğini belirleyen ölçütlere dönüşmektedir. Elektroensefalografi (EEG), beyindeki sinir hücrelerinin istirahatta veya aktivasyon yöntemleri ile uyanması sonucu elde edilen elektriksel potansiyelleri kaydetme yöntemidir. İnsan beynini oluşturan sinir hücrelerinin uyarılması sonucu oluşan gelen potansiyel farktır. İlk olarak 1875 yılında hayvanlar üzerinde yapılan araştırmalarda varlığı tespit edilen beynin elektriksel faaliyetleri, 1929 y1lında Hans Berger tarafından insan beyninde de tespit edilmiştir ve 1930 yılında göz kapaklarının hareketi ile EEG işaretlerinin değiştiği görülmüştür (1). EEG dalgaları, kafa derisi üzerine yerleştirilen özel elektrodlar ve EEG cihazı ile kayıtlanır ve bilgisayar ortamında görünür hale getirilir. EEG dalgaların
Okan Üniversitesi Sağlı Hizmetleri Meslek Yüksekokulu

34959 Akfirat-Tuzla/Istanbul

e-posta: halil.soyal@okan.edu.tr 
genliği ve frekansı farklı aktiviteler ile etkilenmesine bağlı olarak değişiklik gösterir. Ayrıca bireyin yaşına, çevresindeki duyusal uyaranlara, beyindeki hasarlara ve vücudun kimyasal dengesine bağlı olarak değişiklik gösterebilmektedir (2).

EEG kayıtları, klinik teşhislerden beyin fonksiyon anomalilerinin tedavisine kadar giderek artan bir şekilde birçok uygulamalarda kullanılmaktadır (3). Bilgisayarların gelişimi EEG sinyalinin sayısallaşmasını ve değişik yöntemlerle ölçülebilirliğini kolaylaştırmıştır. Tüm bu gelişmelere rağmen EEG'nin gelişmesi gereken yönleri; sinyal gürültü oranının zayıf olması, büyük oranda kişiye özel olması, ölçümler içinde ve/veya arasında değişkenliklere sahip olması ve bilişsel süreç, patolojik durum vb. analizlerinde karmaşık veri analizini gerektirmesidir (4).

Çalışmamız, gerçek anlamda sağlık sektörünün ihtiyacı olan ara kademe teknik elemanı yetiştiren Sağlık Hizmetleri Meslek Yüksekokulunda eğitim gören ve geleceğin sağlık teknikeri olacak öğrencilerin EEG hakkındaki bilgi, tutum ve algılarını tespit etmek amacıyla yapılmıştır.

\section{GEREÇ ve YÖNTEM}

Bu çalışma, 2015-2016 eğitim yılında Okan Üniversitesi Sağlık Hizmetleri Meslek Yüksekokulu programlarında eğitim gören öğrencilerde gerçekleştirilmiştir. Çalışmamızda, öğrencilerin EEG algılarını eksik bilgiden, hatadan ve tahminden ayrıştırarak geçerli ve güvenli ölçülmesini sağlayacak demografik sorular içeren anket kullanılmıştır. Anket, programlardaki öğrenci mevcutları doğrultusunda ders saatleri içerisinde Sağlık Hizmetleri Meslek Yüksekokulu öğrencilerine uygulanmıştır. Soru formunda, EEG algısı ile ilgili olarak öğrencilerin genel yaklaşımlarını, tutumlarını ve EEG ile ilgili olabilecek çeşitli demografik özelliklerini belirlemeye yönelik sorular yer almıştır. Veriler bilgisayar ortamına aktarılarak analiz edilmiştir.

\section{BULGULAR}

Anket çalışması Okan Üniversitesi Sağlık Hizmetleri Meslek Yüksekokulunun farklı programlarında okuyan 740 öğrenciyi kapsamaktadır. Öğrencilerin EEG hakkındaki kavram algılarını ortaya çıkarmak için hazırlanan anketteki sorulara verilen cevaplar dikkate alınarak gruplandırılmıştır. Öğrenci cevapları için frekans ve yüzde dağılımları hesaplanmıştır.
Çalışmaya katılan 740 sağlık teknikeri adayının 381'i $(\% 51,49)$ kadın ve 359'u $(\% 48,51)$ erkektir. Adayların mezun oldukları okullara göre dağılımı incelendiğinde ise 740 adaydan 335'i $(\% 45,27)$ Düz Lise ve 57'si $(\% 7,02)$ İmam Hatip Lisesi mezunudur. Adayların yaş dağılımı incelendiğinde ise 740 adayın 382'si $(\% 51,62)$ 22-25 yaş aralığında olduğu görülmüştür (Tablo 1).

Tablo 1. Öğrencilerin demografik özelliklerini gösteren dağılım

\begin{tabular}{|l|l|l|l|}
\hline \multirow{4}{*}{ Cinsiyet } & & $\mathrm{f}$ & $\%$ \\
\cline { 2 - 4 } & Erkek & 359 & 48,51 \\
\cline { 2 - 4 } & Kadın & 381 & 51,49 \\
\hline \multirow{5}{*}{ Mezun Olduğu Okul } & Düz Lise & 335 & 45,27 \\
\cline { 2 - 4 } & Anadolu Lisesi & 182 & 24,59 \\
\cline { 2 - 4 } & İmam Hatip Lisesi & 57 & 7,703 \\
\cline { 2 - 4 } & Sağlık Meslek Lisesi & 114 & 15,41 \\
\cline { 2 - 4 } & Diğer & 58 & 7,02 \\
\hline Yaş & $18-21$ & 310 & 41,89 \\
\cline { 2 - 4 } & $22-25$ & 382 & 51,62 \\
\cline { 2 - 4 } & $26-$ & 48 & 6,486 \\
\hline & Toplam & 740 & 100 \\
\hline
\end{tabular}

"Sağlık Teknikerliği adayları EEG çekimi kim tarafından yapıldığını biliyor mu?" sorusuna verilen cevaplar karşılaştırıldığında, ankete katılan \%21,35'i kadın, $\% 14,05$ 'i erkek olmak üzere toplam \%35,40 öğrencinin cevabı bildiği, \%64,60’ının bilmediği görülmüştür. Aynı soruyu cevaplayan öğrencilerin yaş dağılımına bakıldığında adayların \%51,62'sinin 22-25 yaş grubu arasında yer aldığ 1 , bu yaş grubundaki adayların sadece \% 14,73' ünün EEG tetkikinin kim tarafından yapıldığı konusunda bilgi sahibi olduğu; \%35,40’ının EEG çekimi konusunda bilgisi olmadığ1 görülmüştür (Tablo 2).

“Sağlık Tekniker adaylarının, EEG cihazının hangi alandaki hastalıkların teşhisinde kullanıldı̆̆ını biliyor musunuz?" sorusuna öğrencilerin verdikleri yanıtlar, cinsiyet, mezun olduğu okul ve yaş dağılımlarına göre incelendiğinde, konuyu bilen ve bilmeyenlerin sayısının birbirine yakın olduğu tespit edilmiştir. Çalışmaya katılan kadın öğrencilerden \%18,11'inin, erkek öğrencilerin $\% 17,43$ ' ünün olmak üzere, toplam \%35,54'ünün hangi alandaki hastalıkların teşhisinde kullanıldığını biliyor oldukları, \%64,46 ile katılımcıların çoğunluğunu oluşturanların ise EEG tetkikinin kullanım alanlarını bilmedikleri saptanmıştır (Tablo 3). 
Tablo 2. Elektroensefalografi çekimi kim tarafından yapıldığı ile ilgili verilen cevap dağılımı

\begin{tabular}{|l|l|l|l|l|l|l|l|l|}
\hline & Evet & $\%$ & Hayır & $\%$ & Fikrim Yok & $\%$ & Toplam & $\%$ \\
\hline Erkek & 104 & 14,05 & 124 & 16,76 & 131 & 17,7 & 359 & 48,51 \\
\hline Kadın & 158 & 21,35 & 144 & 19,46 & 79 & 10,68 & 381 & 51,49 \\
\hline $18-21$ & 131 & 17,7 & 98 & 13,24 & 81 & 10,95 & 310 & 41,89 \\
\hline $22-25$ & 109 & 14,73 & 154 & 20,81 & 119 & 16,08 & 382 & 51,62 \\
\hline $26-\ldots$ & 22 & 2,973 & 16 & 2,162 & 10 & 1,351 & 48 & 6,486 \\
\hline Düz Lise & 127 & 16,89 & 101 & 13,65 & 110 & 14,73 & 337 & 45,27 \\
\hline Anadolu Lisesi & 51 & 6,892 & 67 & 9,054 & 64 & 8,649 & 182 & 24,59 \\
\hline İmam Hatip Lisesi & 22 & 2,973 & 26 & 3,514 & 9 & 1,216 & 57 & 7,703 \\
\hline Sağlık Meslek Lisesi & 43 & 5,811 & 49 & 6,622 & 22 & 2,973 & 114 & 15,41 \\
\hline Diğer & 20 & 2,838 & 25 & 3,378 & 5 & 0,811 & 50 & 7,027 \\
\hline
\end{tabular}

Tablo 3. Elektroensefalografi cihazı bilgi dağılımı

\begin{tabular}{|l|l|l|l|l|l|l|l|l|}
\hline & Evet & $\%$ & Hayır & $\%$ & Fikrim yok & $\%$ & Toplam & $\%$ \\
\hline Erkek & 129 & 17,43 & 110 & 14,86 & 120 & 16,22 & 359 & 48,51 \\
\hline Kadın & 134 & 18,11 & 156 & 21,08 & 91 & 12,3 & 381 & 51,49 \\
\hline Düz Lise & 112 & 15,14 & 109 & 14,73 & 116 & 15,68 & 337 & 45,54 \\
\hline Anadolu Lisesi & 66 & 8,919 & 62 & 8,378 & 54 & 7,297 & 182 & 24,59 \\
\hline İmam Hatip Lisesi & 19 & 2,568 & 28 & 3,784 & 10 & 1,351 & 57 & 7,703 \\
\hline Sağlik Meslek Lisesi & 52 & 7,027 & 45 & 6,081 & 17 & 2,297 & 114 & 15,41 \\
\hline Diğer & 14 & 1,892 & 22 & 2,973 & 14 & 1,892 & 50 & 6,757 \\
\hline $18-21$ & 87 & 11,76 & 124 & 16,76 & 99 & 13,38 & 310 & 41,89 \\
\hline $22-25$ & 151 & 20,41 & 125 & 16,89 & 106 & 14,32 & 382 & 51,62 \\
\hline $26-\ldots$ & 25 & 3,378 & 17 & 2,297 & 6 & 0,811 & 48 & 6,486 \\
\hline
\end{tabular}

"Elektroensefalografi cihazının hangi bölümde kullanıldığını biliyor musunuz?" sorusuna ankete katılan öğrencilerin vermiş oldukları cevapları incelendiğinde, tüm katılımcıların cevaplarının birbirine yakın olduğu görülmüştür. Ancak sağlık teknikeri adaylarının \%65,68'inin bilgi sahibi olmadığı saptanmıştır. Çalışmaya katılan düz lise mezunu öğrencilerin cevaplarına bakıldığında, fikri olmayanların çoğunlukta olduğu gözlenmiştir. Sağlık Meslek Lisesi mezunlarının cevapları incelendiğinde ise sağlık alanında eğitim almalarına rağmen bu öğrencilerin \%6,62' sinin EEG cihazının hangi bölümde kullanıldığını bilmedikleri görülmüştür (Tablo 4).

Sağlık Teknikeri adaylarına "EEG çekimi süresi ne kadardır?" sorusuna verilen cevaplara bakıldığında, öğrencilerin \% 70,7'sinin cevabı bilmediği saptanmıştır. Yaş yoğunluğu olarak fazla olan 22-25 yaş gurubu öğrencilerinde ise yukarıda belirtilenin tersi durum olmasa da bilenlerin katılanların \%19,73 EEG çekiminin insana zarar verdiğini düşünmektedir (Tablo 5).

"Sağlık Teknikeri adaylarına EEG çekimi süresi ne kadardır?" sorusuna verilen cevaplara bakıldığında öğrencilerin \%39,05'inin cevabı bilmediği, \%31,62’ sinin ise bu konuda fikri olmadığı görülmüştür (Tablo 6). Yaş dağılımlarına göre ise; 18-21 ve 22-25 yaş aralığındaki katılımcıların sırasıla \%12,97'si ve \%19,73'ü, EEG tetkikinin insan vücuduna zararlı etkilerinin olduğunu ifade etmişler, aynı yaş aralıklarında bu etkilerin olmadığını düşünenlerin oranları ise sırasıyla \%16,62 ve \%20 şeklinde bulunmuştur. 
Tablo 4. Elektroensefalografi cihazının hangi bölümde kullanıldığı bilgisi dağılımı

\begin{tabular}{|l|c|c|c|c|c|c|c|c|}
\hline & Evet & $\%$ & Hayır & $\%$ & Fikrim Yok & $\%$ & Toplam & $\%$ \\
\hline Erkek & 108 & 14,59 & 125 & 16,89 & 126 & 17,03 & 359 & 48,51 \\
\hline Kadın & 146 & 19,73 & 134 & 18,11 & 101 & 13,65 & 381 & 51,49 \\
\hline Düz Lise & 110 & 14,86 & 103 & 13,92 & 124 & 16,76 & 337 & 45,54 \\
\hline Anadolu Lisesi & 74 & 10 & 66 & 8,919 & 42 & 5,676 & 182 & 24,59 \\
\hline İmam Hatip Lisesi & 15 & 2,027 & 24 & 3,243 & 18 & 2,432 & 57 & 7,703 \\
\hline Sağlı Meslek Lisesi & 45 & 6,081 & 49 & 6,622 & 20 & 2,703 & 114 & 15,41 \\
\hline Diğer & 9 & 1,216 & 20 & 2,703 & 21 & 2,838 & 50 & 6,757 \\
\hline $18-21$ & 92 & 12,43 & 117 & 15,81 & 101 & 13,65 & 310 & 41,89 \\
\hline $22-25$ & 146 & 19,73 & 122 & 16,49 & 114 & 15,41 & 382 & 51,62 \\
\hline $26-\ldots$ & 16 & 2,162 & 20 & 2,703 & 12 & 1,622 & 48 & 6,486 \\
\hline
\end{tabular}

Tablo 5. Elektroensefalografi çekimi süresi bilgisi dağılımı

\begin{tabular}{|l|l|l|l|l|l|l|l|l|}
\hline & Evet & $\%$ & Hayır & $\%$ & Fikrim Yok & $\%$ & Toplam & $\%$ \\
\hline Erkek & 113 & 15,27 & 143 & 19,32 & 103 & 13,92 & 359 & 48,51 \\
\hline Kadın & 104 & 14,05 & 146 & 19,73 & 131 & 17,7 & 381 & 51,49 \\
\hline Düz Lise & 110 & 14,86 & 111 & 15,14 & 114 & 15,27 & 337 & 45,27 \\
\hline Anadolu Lisesi & 58 & 7,838 & 79 & 10,68 & 45 & 6,081 & 182 & 24,59 \\
\hline İmam Hatip Lisesi & 13 & 1,757 & 25 & 3,378 & 19 & 2,568 & 57 & 7,703 \\
\hline Sağlık Meslek Lisesi & 28 & 3,784 & 45 & 6,081 & 41 & 5,541 & 114 & 15,41 \\
\hline Diğer & 8 & 1,081 & 27 & 3,784 & 15 & 2,162 & 50 & 7,027 \\
\hline $18-21$ & 78 & 10,54 & 125 & 16,89 & 107 & 14,46 & 310 & 41,89 \\
\hline $22-25$ & 127 & 17,16 & 141 & 19,05 & 114 & 15,41 & 382 & 51,62 \\
\hline $26-\ldots$ & 12 & 1,622 & 23 & 3,108 & 13 & 1,757 & 48 & 6,486 \\
\hline
\end{tabular}

Tablo 6. Elektroensefalografi çekiminin insan vücuduna herhangi bir zararı var mı bilgi dağılımı

\begin{tabular}{|l|l|l|l|l|l|l|l|l|}
\hline & Evet & $\%$ & Hayır & $\%$ & Fikrim Yok & $\%$ & Toplam & $\%$ \\
\hline Erkek & 105 & 14,19 & 145 & 19,59 & 109 & 14,73 & 359 & 48,51 \\
\hline Kadın & 147 & 19,86 & 151 & 20,41 & 83 & 11,22 & 381 & 51,49 \\
\hline Düz Lise & 133 & 17,84 & 125 & 16,89 & 79 & 10,54 & 337 & 45,27 \\
\hline Anadolu Lisesi & 59 & 7,973 & 76 & 10,27 & 47 & 6,351 & 182 & 24,59 \\
\hline İmam Hatip Lisesi & 9 & 1,216 & 27 & 3,649 & 21 & 2,838 & 57 & 7,703 \\
\hline Sağlık Meslek Lisesi & 41 & 5,541 & 46 & 6,216 & 27 & 3,649 & 114 & 15,41 \\
\hline Diğer & 10 & 1,486 & 22 & 2,973 & 18 & 2,568 & 50 & 7,027 \\
\hline $18-21$ & 96 & 12,97 & 123 & 16,62 & 91 & 12,3 & 310 & 41,89 \\
\hline $22-25$ & 146 & 19,73 & 148 & 20 & 88 & 11,89 & 382 & 51,62 \\
\hline $26-.$. & 10 & 1,351 & 25 & 3,378 & 13 & 1,757 & 48 & 6,486 \\
\hline
\end{tabular}




\section{TARTIŞMA}

Daha çok algı değerlendirmesi çalışması olarak yürüttüğümüz bu çalışmada, başka benzeri çalışmalar ve veriler olmadığı için sonuçları geniş popülasyon temelli değerlendirebilmemiz güçtür. Elde ettiğimiz sonuçların, özellikle Elektronörofizyoloji durumu konusunda fikir verdiğini düşünmekteyiz. Bu çalışmada amacımız, toplumun geneline göre sağlık alanında daha bilgili ve deneyimli olduğu düşünülen Sağlık Hizmetleri Meslek Yüksekokulları öğrencilerinin yaş, cinsiyet ve eğitim düzeyleri dikkate alınarak EEG ile ilgili algılarını değerlendirmekti.

18-25 yaş aralığında katılımın daha fazla olduğu bu anket çalışmasında katılımcılara EEG çekiminin kim tarafından yapıldığı, EEG çekim süresi, EEG kullanım alanları, tetkikin zararlı bir tetkik olup olmadığı gibi oldukça temel bilgileri içeren sorular yönlendirilmiş ve cevaplar yaş, cinsiyet ve eğitim durumlarına göre değerlendirilmiştir. Elde edilen cevaplar ile katılımcıların doğru olmayan bilgilere sahip oldukları ve önemli bir kısmının da bilgi sahibi olmadığı saptanmıştır. Yaş, cinsiyet ve eğitim durumunun bu sonuçlar üzerinde farklı bir etkiye sahip olmadığı gözlenmiştir.

\section{SONUÇ}

Sağlık Hizmetleri Meslek Yüksekokulu öğrencilerinin, sağlık alanı ile ilgili konularda daha duyarlı olabilecekleri ile ilgili ön düşüncemizde yanıldığımızı gördük. Özellikle Sağlık Meslek Liselerinden gelen öğrenciler bu konudaki beklentimizi karşılamadı. Benzer çalışmaların daha sık ve farklı okullarda yapılmasının yararlı olacağını ve sağlık alanında çoğalan teknisyen/tekniker gereksiniminde, daha donanımlı ve yetkin kadroların yetişmesine katkı sağlayacağını düşünmekteyiz.

\section{KAYNAKLAR}

1. Yazgan, E., ve Korürek, M., Tıp Elektroniği. İTÜ Matbaas1, 220 s, İstanbul,1996.

2. Malmivuo, J.,Plonsey, R., Bioelectromagnetism Principles and Applications of Bioelectric and Biomagnetic Fields. Oxford UniversityPress, 599P,Oxford.1995.

3. Prior P. and Maynard D., Monitoring cerebral function : long-term monitoring of EEG and evoked potentials. New York: Elsevier, 1986

4. Schlögl A, Slater M, Pfurtscheller G. Proceedings of the 5th International Workshop on Presence,;1-7 ,2002 
